Research Article

\title{
Effect of Silicone Oil on Dispersion and Low-Temperature Fracture Performance of Crumb Rubber Asphalt
}

\author{
Nonde Lushinga (D), Liping Cao $(\mathbb{D}$, and Zejiao Dong \\ School of Transportation Science and Engineering, Harbin Institute of Technology, Huanghe Road 73\#, Nangang District, \\ Harbin 150090, Heilongjiang, China \\ Correspondence should be addressed to Liping Cao; caoliping79@163.com
}

Received 12 July 2019; Accepted 10 September 2019; Published 17 October 2019

Academic Editor: Hom Kandel

Copyright ( 92019 Nonde Lushinga et al. This is an open access article distributed under the Creative Commons Attribution License, which permits unrestricted use, distribution, and reproduction in any medium, provided the original work is properly cited.

Low-temperature cracking is one of the major pavement distresses in cold regions. To reduce the prevalence of such cracks, crumb rubber modified asphalt (CRMA) has been applied for a long time. However, CRMA experiences compatibility and segregation problems with asphalt. Silicone oil has long been seen to improve compatibility and segregation problems of polymers in asphalt, but its benefits on low temperature performance of crumb rubber asphalt have not been explored. Furthermore, silicone oil can be obtained as virgin or recycled from industrial transformers; however, the recycled silicone oil's influence on low-temperature crack performance of asphalt has also not been explored. Therefore, the purpose of this study was to investigate the effect of recycled silicone oil (SO) on dispersion and low-temperature fracture performance of crumb rubber asphalt. The fracture mechanics-based single-edge notch beam (SENB) test was performed at temperatures of $-12^{\circ} \mathrm{C},-18^{\circ} \mathrm{C}$, and $-24^{\circ} \mathrm{C}$. In addition, fluorescence microscopy (FM), atomic force microscopy (AFM), and Fourier-transform infrared (FTIR) experiments were also conducted. Results show that the addition of SO to CRMA increases displacement, fracture energy, and fracture toughness at low temperature while it decreases stiffness which reduces cracking. In addition, AFM results show that surface roughness increases with the addition of SO which indicates that bonding of asphalt and rubber particles had also improved. FM also confirmed that dispersion of rubber particles had improved with addition of silicone oil. FTIR results revealed that asphalt samples with SO treatment were hydrophobic which potentially repels water ingress and delays the freezing of asphalt. Lastly, statistical analysis revealed that the influence of silicone oil on low-temperature performance of rubber asphalt was significant. Therefore, the study concluded that fracture cracking resistance is improved by addition of silicone oil to crumb rubber asphalt.

\section{Introduction}

In cold regions, low-temperature cracking has been one of the major pavement distresses $[1,2]$. Pavements often experience thermal contraction when temperatures drop to subzero. At low temperature, asphalt becomes brittle and the generated thermal stress is only relieved when the transverse crack is initiated. This cracking gives rise to premature failure of the pavement and poor rideability [3]. To reduce this type of distress and maintenance costs, asphalt mixtures should be designed and built with materials that are able to sustain the stresses generated by both low-temperature conditions and vehicular loads.

Crumb rubber (CR), a waste material from vehicular tires, has been suggested as an asphalt modifier for pavement applications to improve low-temperature performance. For example, many researchers have studied the performance of the CR asphalt binder. Results in all respects have led to the conclusion that crumb rubber improves mechanical properties of asphalt binders, particularly low temperature performance. This performance is attributed to several factors such as decrease in stiffness of rubber asphalt at low temperature due to improvement in aging susceptibility of the asphalt binder; low sensitivity of rubber to low temperature; and good elasticity properties [4-10].

Despite the enhanced performance attributed to crumb rubber asphalt, CR as an asphalt modifier has a setback of compatibility and separation problems with asphalt binders. In quest to solve the problem of separation, the Federal Highway Administration (FHWA) in 1998 prepared a crumb rubber 
asphalt which was chemically modified. The prepared asphalt binders had increased separation resistance especially during hot storage when compared to conventional crumb rubber asphalt binders. This was achieved by modifying the crumb rubber with chemical additives which makes CR to mix and disperse well in asphalt matrix [11].

Previous studies used virgin silicone oil to prepare chemical crumb rubber asphalt. Results suggested that silicone oil can improve both dispersion and mechanical properties of crumb rubber asphalt binders [12].

Silicone oil whose important component is polydimethysiloxane (PDMS) has excellent thermal stability and high- and low-temperature properties which make it suitable as a compatibilizer of choice at low-temperature conditions. This polymetric material is mostly used as lubricants and coolants in electrical appliances such as industrial transformers. Therefore, silicon oil can be cheaply purchased locally since it is discharged from these industrial transformers as waste oil, often reclaimed and regenerated through the industrial process to remove contaminants to make it suitable for use. To date, no studies exist on the use of silicone oil to improve low-temperature performance of crumb rubber asphalt, hence the motivation for this research.

Zhihao et al. [13] stated that most polymers such as steryne-butadieme-styrene (SBS), polyphosphate (PPA), polyethylene (PE), and vinyl acetate B-copolymer (EVA) have segregation problems when blended with asphalt. The author further noted that maleic anhydride and PPA often cause adverse effects on low-temperature performance when added to asphalt. Therefore, polydimethysiloxane (PDMS), in particular dimethyl silicone oil, was suggested as an alternative material that can be used to solve the problem of segregation of polymers with asphalt at low-temperature conditions because of its excellent thermal stability, low-temperature performance effect, excellent flexibility, and weather resistance. Besides that, no studies were undertaken in that regard.

However, some scholars such as Li et al. [14] studied the performance of composite asphalt materials where they added dicumyl peroxide and silicone oil (used to enhance compatibilization) into high density polyethelene/crumb rubber modified (HDPE/CRM) composite mixed with ethylene propylene diene monomers (EPDM). It was found that silicone oil encapsulates the scrap rubber powder particles to form a soft, thick layer between CRM and the polymer matrix. This liquid layer in the polymer and filler could inhibit fracture phenomena (i.e., crack formation and propagation). Under this consideration, the encapsulation of silicone oil should have released the stress concentration around the CR powder particles and hence the mechanical properties are improved.

In the recent past, an investigation of coated polydimethysiloxane (PDMS) or room temperature vulcanised silicone rubber (RTV) with layered double hydroxides (LDHs) to produce superhydrophobicity (super-water repellent) coatings was applied to asphalt mixtures by Peng et al. [15]. The results suggest that the freezing time of asphalt mixtures with RTV/LDHs is extended by about 3 times when compared with asphalt mixtures without RTV/LDHs coatings.
Furthermore, other studies have demonstrated that silicones can be used in improving moisture and thermal aging resistance of asphalt mixtures because of their superior hydrophobicity and weather resistance properties [16, 17].

On the other hand, it is worth noting that oil-based softening agents and rejuvenators have also been used to improve low-temperature cracking resistance. For instance, Zhang et al. [18] used bio-oil-based rejuvenator to improve the low-temperature performance of aged asphalt binder. The author found that biorejuvenator softened aged asphalt significantly decreased the rutting index at a temperature of $52^{\circ} \mathrm{C}$ to $76^{\circ} \mathrm{C}$ and restored low-temperature crack resistance.

Overall, extant literature has confirmed that no studies have been undertaken to investigate the influence of recycled silicone oil on low-temperature cracking performance of rubber asphalt. Hence, the research gap exists for further study.

\section{Objectives and Scope}

The purpose of this paper was to investigate the effect of silicone oil on dispersion and low-temperature fracture performance of crumb rubber-asphalt binders. The study is important as it contributes towards efforts of providing sustainable paving materials while improving asphalt performance yet even further. The asphalt binders were evaluated at low temperatures ranging from -12 to $24^{\circ} \mathrm{C}$. The specific objectives and scope of the research are summarised as follows:

(1) To evaluate the effect of silicone oil on crumb rubber asphalt's low-temperature fracture performance based on single-edge notch beam (SENB) test

(2) To understand the morphology of crumb rubber modified asphalt samples based on fluorescence microscopy (FM) and atomic force microscopy (AFM) tests

(3) To determine the molecular structure of silicone oil and crumb rubber modified asphalt samples based on Fourier-transform infrared (FTIR) test

(4) To evaluate the effect of notch depth on low-temperature cracking of crumb rubber asphalt containing silicone oil based on the SENB test

(5) To conduct statistical test on laboratory experimental results in order to determine the significance of the findings.

\section{Materials}

In this study, asphalt binder $60-80$ penetration grade bitumen was used to prepare crumb rubber modified asphalt samples. Silicone oil was treated with crumb rubber asphalt to produce two replicates for one sample, while for another, crumb rubber asphalt without silicone oil was used to produce replicates for control experiment samples. Materials used in this research can be found in Tables 1-3. The binders were tested without being subjected to short- or long-term aging. As an assumption, it was envisaged that aging of 
TABle 1: Physical properties of silicone oil (SO).

\begin{tabular}{lcccc}
\hline Technical properties & Colour & Viscosity $25^{\circ} \mathrm{C}$ & Density $\left(\mathrm{kg} / \mathrm{m}^{3}\right)$ & Molecular weight \\
\hline Description & Colourless & 1000 & 0.97 & 28000 \\
\hline
\end{tabular}

TABLE 2: Basic material properties asphalt binders.

\begin{tabular}{lcccc}
\hline Binder tests & Neat asphalt & Neat + 18\% CR & Neat + 18\% CR + 3\% SO & $\begin{array}{c}\text { Rubber asphalt } \\
\text { specification limits }\end{array}$ \\
\hline Penetration: $4^{\circ} \mathrm{C}, 200 \mathrm{~g}, 60 \mathrm{sec}, 1 / 10 \mathrm{~mm}$ (ASTM D5) & 70 & 49 & 60 & 10 \\
Softening point ASTM D36 $\left({ }^{\circ} \mathrm{C}\right)$ & 45 & 65 & 62 & 57 \\
Ductility @ $15^{\circ} \mathrm{C}(\mathrm{cm})$ & 100 & - & - & - \\
\hline
\end{tabular}

TABLE 3: Gradation of crumb rubber.

\begin{tabular}{|c|c|c|c|c|c|}
\hline Sieve & $\# 30$ & $\# 40$ & $\# 50$ & $\# 100$ & $\# 200$ \\
\hline$\%$ passing & 100 & $90-100$ & 65 & 14 & 3 \\
\hline
\end{tabular}

asphalt was not going to significantly change the conclusions obtained from the study. In addition, the silicone oil and crumb rubber mesh \#40 were used to prepare crumb rubber modified asphalt.

\section{Experimental Test Methods}

4.1. Preparation of Samples. About 18 percent content of crumb rubber by weight was added to asphalt binder. One of the blends was reacted with recycled silicone oil during shearing, while the other was prepared as conventional crumb rubber asphalt binder without silicone oil. The crumb rubber was added slowly and followed by silicone oil (3\% by weight of the binder), and the mixture was sheared for one hour at $175^{\circ} \mathrm{C}$.

After preparation, the binders were poured into the singleedge notch beam test moulds and cooled to $0^{\circ} \mathrm{C}$ and quickly taken from the moulds measuring $127 \mathrm{~mm} \times 6.35 \mathrm{~mm} \times$ $12.7 \mathrm{~mm}$ for length, width, and depth, respectively. The depth of the precrack was $2.8 \mathrm{~mm}$. Both the precracked and the uncracked samples were used to facilitate the study of the effect of silicone oil on crumb rubber modified asphalt's performance on low-temperature cracking. Before testing, each specimen was conditioned in cold bath to testing temperatures $-12^{\circ} \mathrm{C}, 18^{\circ} \mathrm{C}$, and $-24^{\circ} \mathrm{C}$, respectively. To simplify the experiment, physical hardening both on unmodified asphalt and crumb rubber modified asphalt (with and without silicone oil) was tested after 1 hour of conditioning at respective temperatures.

4.2. Fourier-Transform Infrared (FTIR) Test. FTIR can be used for identifying polymer additives in asphalt binder matrix. In addition, FTIR offers accurate data concerning oxygenation rate, aliphaticity, and aromaticity [19]. Thus, the FTIR spectroscopy was conducted using a Jasco FTIR4200 spectrometer, with 32 numbers of scan and the resolution of $4 \mathrm{~cm}^{-1}$. To prepare the control and modified asphalt samples for the FTIR experiment, the conventional crumb rubber asphalt samples and the silicone-modified crumb rubber asphalt samples were heated to $180^{\circ} \mathrm{C}$ until liquid enough to be poured. With the aid of a brush, the liquefied asphalt binders were then painted onto the surface of a silicon slide to create a uniform asphalt coating of $0.5 \mathrm{~mm}$ approximate thickness.

Prepared samples were tested, and the concentration of the functional groups associated with silicone oil absorption in asphalt binder was deduced from the intensity of the absorption bands. Further, the structural functional index for aromatics was determined with a view of understanding the contribution of silicone to the aromatic content of asphalt binder.

4.3. Fluorescence Microscopy Test. In order to study the morphology of CRMA, fluorescent microscopy (FM) was used by determining the rubber particles distribution in asphalt. The FM test is premised on the principle that polymers undergo swelling owing to absorption of some of the key constituents of the base bitumen. Similarly, in this study, FM was used to study the morphology of CRMA with and without silicone oil treatment so as to observe the quality and particles dispersion in the binder. Samples were placed on glass slides and taken to the laboratory for testing with magnification of $100 \mu \mathrm{m}$.

4.4. Atomic Force Microscopy Analysis. In this study, AFM was used to determine the surface roughness $(\mathrm{Ra})$ of asphalt samples based on equation (1). Furthermore, the morphological distribution of rubber particles in asphalt binder was evaluated. CRMA samples with and without silicone oil were prepared by pouring hot binder on the thin clean glass slides and allowing the binder to flow on the glass slide. Experiments were conducted at a temperature of $30^{\circ} \mathrm{C}$. Both $3 \mathrm{D}$ height images as well as $2 \mathrm{D}$ phase images were obtained:

$$
\mathrm{Ra}=\frac{1}{N} \sum_{j=1}^{N} Z_{i}
$$

where $Z_{i}$ is the current height value and $N$ is the number of points within the scan area.

4.5. Single-Edge Notch Beam (SENB) Testing. A fracture mechanics-based SENB test was carried out on a three-point bending test apparatus that was placed on a bending beam rheometer (BBR) chamber mounted. The BBR water 
chamber was utilized solely for conditioning samples to required temperatures. The temperature inside the water chamber was controlled with water supply and held within $0.3^{\circ} \mathrm{C}$ from the desired value. A displacement rate of $0.01 \mathrm{~mm}$ was applied to break the sample at a rate that had previously been determined to be convenient.

The justification for the choice of the SENB test was premised on the fact that good fracture parametric properties of asphalt materials are important in building longlasting asphalt pavements in cold regions [1]. Furthermore, although the BBR test has been seen to be sound in investigating low-temperature performance of unmodified binders, it is not quite so for modified binders [5]. Strategic Highway Research Program (SHRP) researchers recognized that a full fracture mechanics-based evaluation at appropriate temperatures and rates of loading should be done to evaluate a binder for fracture performance [20]. When field results of asphalt mixtures, in particular BBR-SENB test results, were compared with fracture properties, researchers concluded that the BBR test should be complimented with fracture tests [21]. The SENB test therefore offers results that correlates well with field experimentations and thus was used in this study.

\section{Fracture Approach}

The fracture approach is based on fracture mechanics theory and is used to estimate the resistance of the material to crack propagation [2]. In this theory, a preexisting crack or notch is punched in the specimen and used to reduce the effective strength of the material by amplifying the stress level near the crack. The parametric properties obtained with this theory are fracture energy $\left(G_{\mathrm{f}}\right)$ and fracture toughness $\left(K_{\mathrm{Ic}}\right)$. The single-edge notch test (SENB) test has been developed based on the theory of fracture mechanics and ASTM E 399 testing protocols [5]. This test assumes linear elastic fracture mechanics' conditions. Equations (2) and (3) were used for calculations of fracture toughness and fracture energy. A low fracture toughness value is an indication that materials are going through brittle fractures, while high values of fracture toughness are a sign of ductility improvement. A large deformation on the load-displacement curve and fracture energy is an indication of superior crack resistance of the asphalt binder. Fracture toughness was calculated according to the following equation [5]:

$$
K_{\mathrm{Ic}}=\frac{P_{\mathrm{f}} S}{b W^{3 / 2}}\left[\frac{2(a / W)^{1 / 2}\left\{1.99-(a / W)(1-(a / W))\left[2.15-3.93(a / W)+2.7(a / W)^{2}\right]\right\}}{2(1+2(a / W))(1-(a / W))^{3 / 2}}\right]
$$

where $K_{\mathrm{Ic}}=$ fracture toughness under plain-strain conditions $\left(\mathrm{N} / \mathrm{m}^{3 / 2}\right), P_{\mathrm{f}}=$ applied failure load $(N), S=$ load span $(\mathrm{m}), b=$ specimen thickness $(\mathrm{m}), W=$ specimen height $(\mathrm{m})$, and $a=$ notched depth (m)

Force/load-displacement results were used to calculate a stiffness modulus assuming the beam was un-notched by using equation (3). Using the stiffness modulus, fracture energy was calculated from the fracture toughness. Poisson's ratio needed in the calculation was assumed to be equal to 0.5 (purely elastic materials). The values of fracture energy were obtained from the determined fracture toughness and the stiffness modulus, and Poisson's ratio was assumed to be 0.5 for the asphalt binder according to Hoare and Hesp [5]:

$$
G_{\mathrm{Ic}}=\frac{K_{\mathrm{Ic}}^{2}\left(1-v^{2}\right)}{E}=0.75 \frac{K_{\mathrm{Ic}}^{2}}{E},
$$

where $G_{\text {Ic }}=$ fracture energy or critical elastic energy release rate $\left(\mathrm{J} / \mathrm{m}^{2}\right), E=$ Young's modulus $\left(K_{\mathrm{Ic}}\right.$ test $\left.\left(\mathrm{N} / \mathrm{m}^{2}\right)\right)$, and $v=$ Poisson's ratio.

\section{Results and Discussion}

6.1. Fourier-Transform Infrared (FTIR) Result Analysis. Functional groups of silicone oil in crumb rubber asphalt were determined using the FTIR test. The analysis of infrared spectrum of various materials including silicone oil, base and crumb rubber asphalt, and crumb rubber asphalt modified with silicone oil is shown in Figure 1. The study revealed that the peaks observed in the region of $2850-2960 \mathrm{~cm}^{-1}$ are typically $\mathrm{C}-\mathrm{H}$ stretching vibrations. Those observed around 1400$1500 \mathrm{~cm}^{-1}$ and $1300-1350 \mathrm{~cm}^{-1}$ are C-H symmetric deforming vibrations. The peaks in the region within $1000-1100 \mathrm{~cm}^{-1}$ are $\mathrm{Si}-\mathrm{O}-\mathrm{Si}$ bond vibrations. The Si-O bond in silicone oil forms the main chain that makes silicone oil to have high hydrophobicity and chemical durability which ensures that the silicone oil generally being able to be applied in the asphalt $[17,22]$.

Comparing the infrared spectra of crumb rubber with and without silicone oil, it was observed that new absorption peaks exist in the infrared spectra of crumb rubber asphalt containing recycled silicone oil which were $2964 \mathrm{~cm}^{-1}$, $1258 \mathrm{~cm}^{-1}, 1009 \mathrm{~cm}^{-1}$, and $788 \mathrm{~cm}^{-1}$, respectively. At $788 \mathrm{~cm}^{-1}$, the peaks correspond to Si-C bond. The identified absorption peaks represent polydimethysiloxane or silicone oil [23]. After adding silicone oil to crumb rubber asphalt, the peaks did not disappear in asphalt. This meant that the reaction between crumb rubber and silicone oil was chemical and not physical. All the new absorption peaks have corresponding peaks in silicone oil spectrum [24].

Additionally, the aromatic index $(\mathrm{C}=\mathrm{C})$ was determined using the equation provided elsewhere [18]. Zhang used the aromatic index to determine the degree of restoration of aged binders by applying bio-oil-based rejuvenator to improve the low-temperature performance. It was found that bio-oil restores the aged asphalt and increases temperature susceptibility of asphalt, thereby enduring higher thermal stress caused by cooling. In our study, the aromatic index for 


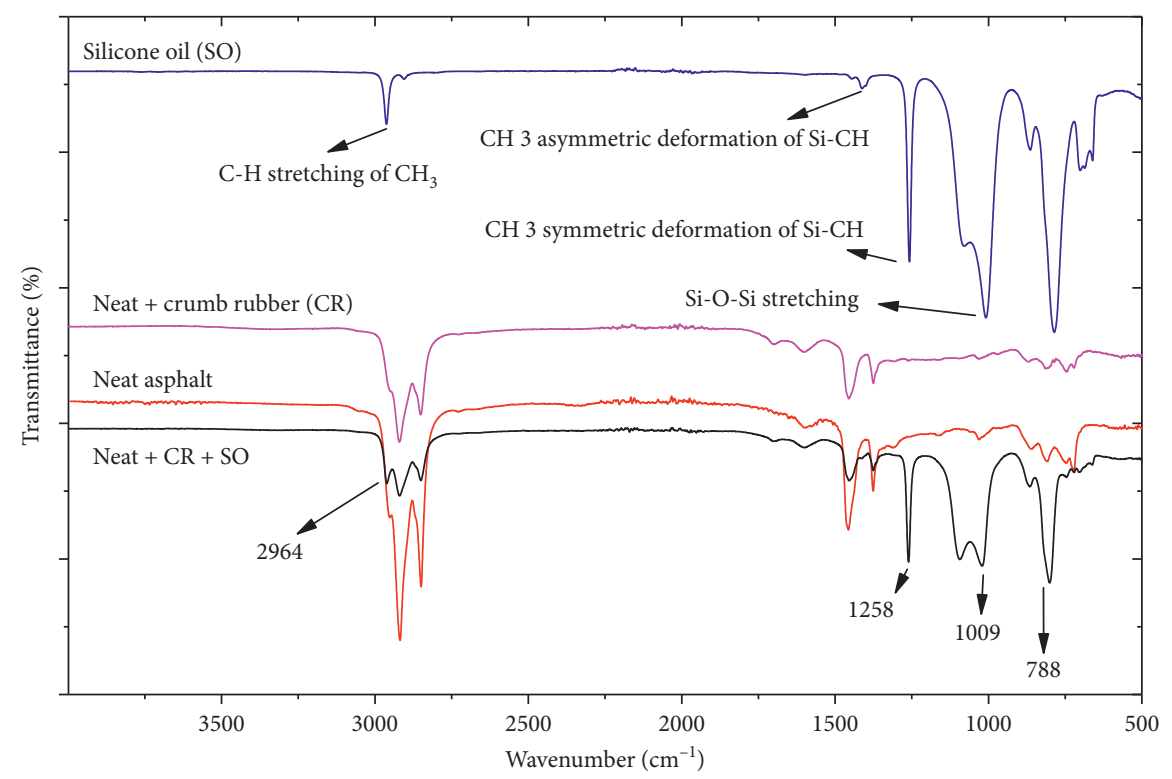

FIGURE 1: FTIR spectrum of silicone oil, neat asphalt, and crumb rubber asphalt modified with silicone oil.

asphalt binder was calculated to determine the content of aromatics in asphalt binder with and without silicone oil treatment. The results revealed that the aromatic index for crumb rubber asphalt with and without silicone oil was 1.0 and 0.6 , respectively. This result gave rise to the conclusion that the addition of silicone oil to crumb rubber asphalt increases the aromatic content and indices significantly. According to Kanabar, highway pavements that do not experience the spate of thermal distress are built with asphalt cements that have high IR aromatic indices or have more aromatics [25]. In addition, the increase in aromatic content also decreases the dynamic modulus of the binder [18]. Therefore, the high IR aromatic index found in this study suggests that low-temperature cracking performance can be improved with addition of silicone oil to asphalt binder.

6.2. Atomic Force Microscopy (AFM) Result Analysis. To evaluate the morphology of asphalt samples, the AFM test was used. The AFM topographical images in Figure 2 gave rise to the following observations: the bee-like structures were CR particles in asphalt binder. Based on equation (1), the average roughness for crumb rubber asphalt without silicone oil was calculated as $0.37 \mathrm{~nm}$, whereas average roughness for crumb rubber asphalt containing silicone oil was $1.29 \mathrm{~nm}$, respectively. The increase in surface roughness of asphalt indicated that there was a change in the microstructure of the asphalt samples after addition of silicone oil. In our study, the increased surface roughness of crumb rubber asphalt with silicone oil indicates improved bonding between rubber particles and asphalt which may lead to continuous rubber particles dispersion in asphalt. Visual comparison of AFM images confirmed that the addition of silicone oil to crumb rubber asphalt greatly influenced the observed microstructure and showed a continuous homogeneity of rubber particles dispersion in asphalt. Conversely, AFM topographical images for CR asphalt sample without silicone oil revealed that rubber particle distribution was not homogeneous.

6.3. Fluorescence Microscopy (FM) Result Analysis. The results of AFM were further confirmed by FM analysis. The influence of silicone oil on the dispersion of crumb rubber particles in asphalt binder was studied using the FM test which was conducted on two crumb rubber asphalt samples with and without silicone oil. From Figure 3, results of FM images revealed that the crumb rubber modified binders with silicone oil showed uniformly dispersed rubber particles in asphalt. Conversely, images of dispersion for conventional crumb rubber asphalt without silicone oil showed noncontinuous bitumen matrix.

6.4. Effect of Silicone Oil on Low-Temperature Performance of Crumb Rubber Asphalt Binder. Figure 4 shows that loaddisplacement curves, stiffness modulus, fracture toughness, and fracture energy values at three temperatures for the crumb rubber asphalt binders gave rise to the following observations.

The results of load and displacement curve found that the addition of silicone oil to samples leads to increase in displacement. Asphalt binders having lower deflection at fracture perform very poorly in the field as regards the thermal cracking [4]. Therefore, higher deflection values in our study indicate good low-temperature cracking resistance. In addition, the addition of silicone oil also increases stiffness modulus of the sample. High stiffness modulus asphalt mixes at low temperature are prone to cracking [6]. Therefore, the lower stiffness modulus obtained in our study is an indication of improved lowtemperature performance of crumb rubber containing silicone oil.

It is also worth noting that rubber asphalt with silicone oil did not break at $-12^{\circ} \mathrm{C}$ owing to its increased lowtemperature resistance. This result demonstrated the effect 


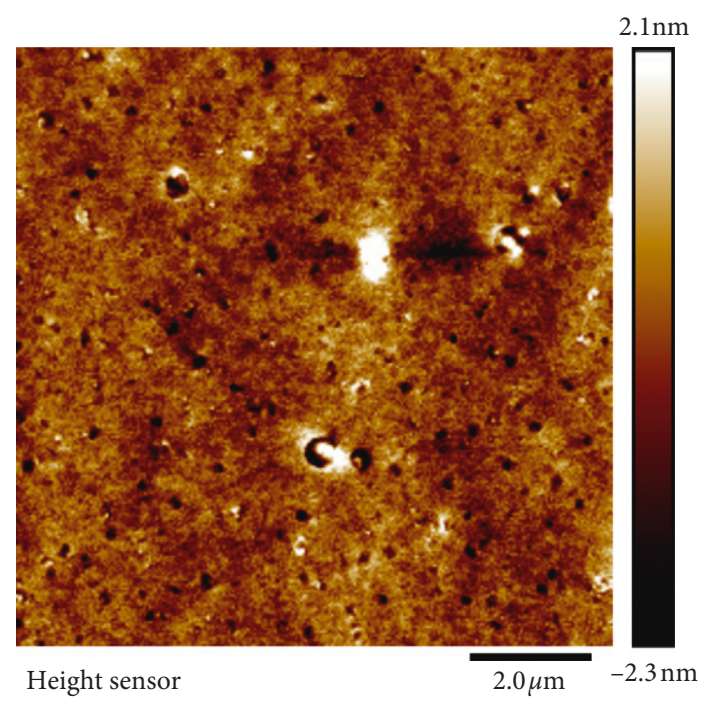

(a)

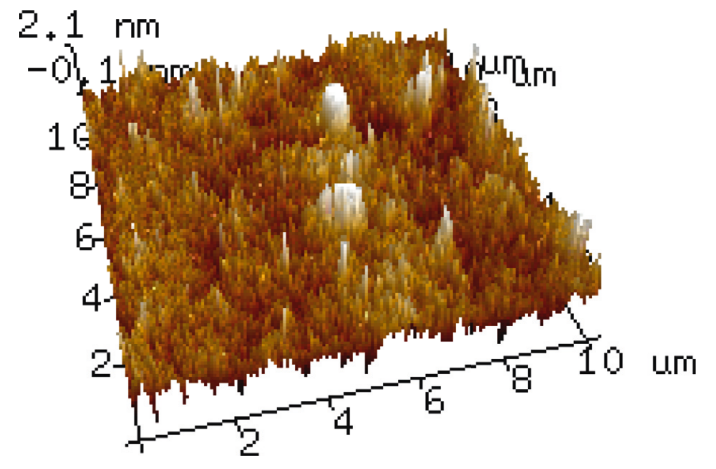

(c)

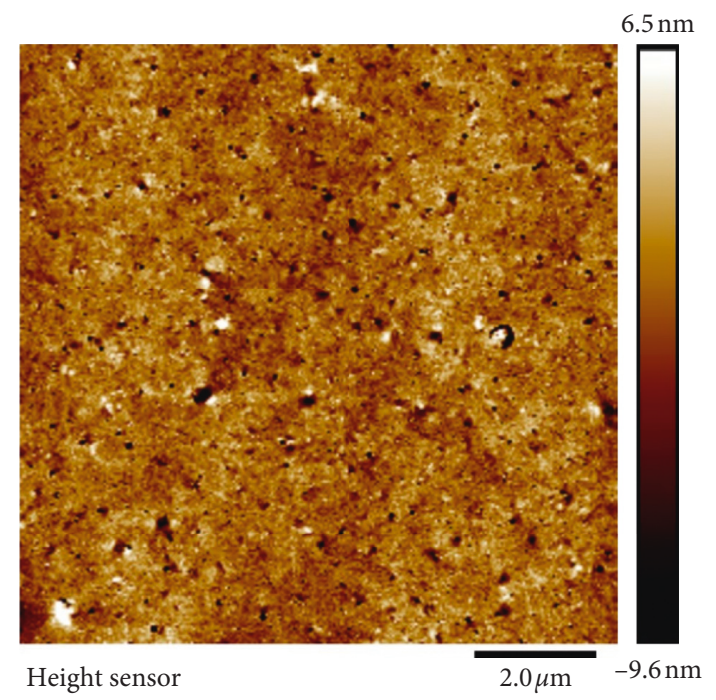

(b)

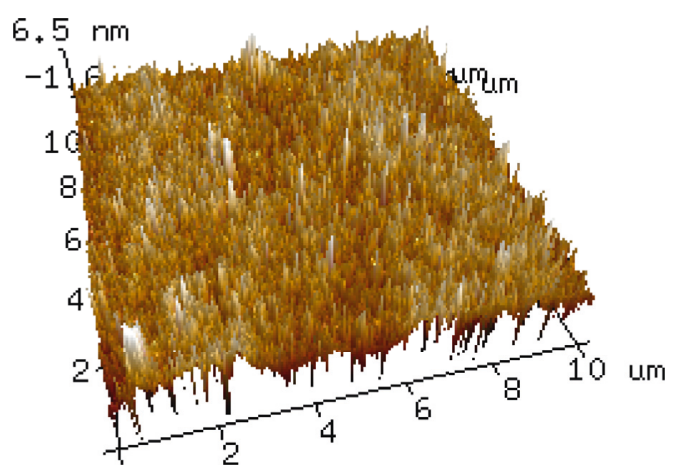

(d)

FIgURe 2: AFM images of crumb rubber asphalt (with and without silicone oil). (a) Neat + CR-2D AFM images. (b) Neat + CR + SO-2D AFM images. (c) Neat + CR 3D AFM images. (d) Neat + CR + SO 3D AFM images.

of silicone oil on low-temperature performance of crumb rubber asphalt binders having high fracture energy would perform very well in the field in terms of thermal cracking resistance. This was added to show that our findings agree with other researchers [2]. In our study, results have demonstrated that the addition of silicone oil to rubber asphalt increased the fracture energy; therefore, we found that the increase in fracture energy demonstrated that samples modified with silicone oil have superior crack resistance.

Fracture toughness is yet another critical parameter used in evaluating low temperature performance of asphalt binders in SENB test. Increased fracture toughness values at low temperatures such as $-20^{\circ} \mathrm{C}$ in polymer modified asphalt mixtures imply that resistance to fracture has increased. Some polymers make asphalt less brittle at low temperatures, and therefore polymer modified asphalt (PMA) concretes are expected to become tougher than normal asphalt concrete at low temperatures. The improved tensile property allows greater resistance to material cracking [26]. Similarly, in our study, it has been established that adding 3\% content of silicone oil to crumb rubber asphalt resulted in increased fracture toughness of the binder than binders without silicone oil. This demonstrates that tensile property has improved, leading to greater low-temperature crack resistance.

6.5. Low-Temperature Performance Analysis of Crumb Rubber Asphalt considering Notched and Unnotched Conditions. To investigate the effect of notch on low-temperature performance of crumb rubber asphalt, the samples with and without a notch were subjected to fracture testing after 1hour conditioning in cold bath. The study gave rise to the following observations.

As seen in Figure 5, the load-displacement curve results show an increase in stiffness modulus for unnotched samples of crumb rubber modified with silicone oil when compared with the unnotched samples. The preexisting crack renders the sample vulnerable to cracking; therefore, unnotched samples will most likely have delayed cracking than the notched samples.

Additionally, the fracture toughness $K_{\mathrm{Ic}}$ and fracture energy $G_{\text {Ic }}$ increased with an increase in temperature from -24 to $-12^{\circ} \mathrm{C}$; this indicates that less potential fracture energy is needed for crack propagation at lower temperatures. Fracture energy and fracture toughness also increased 


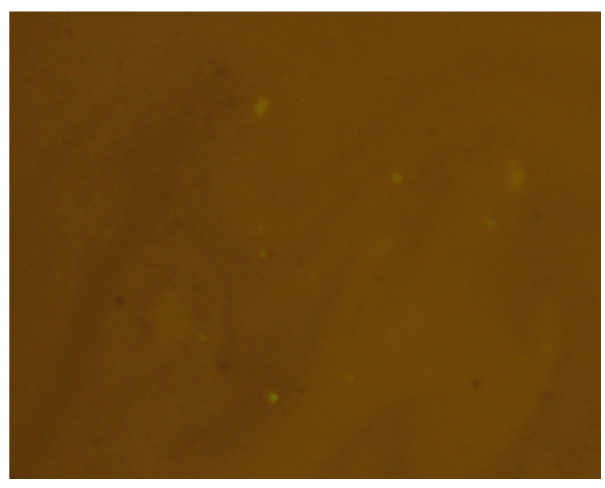

(a)

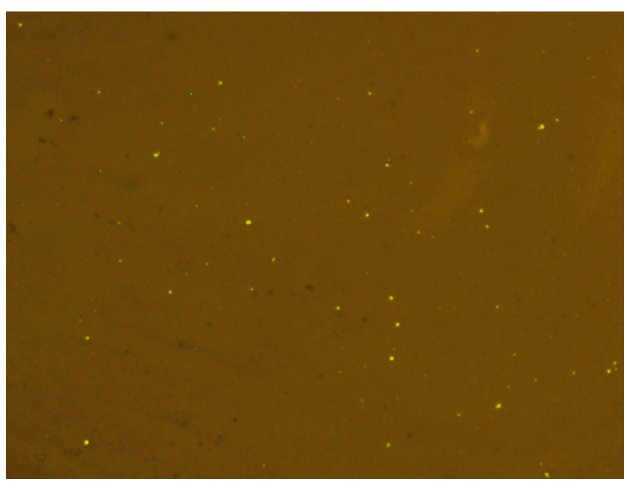

(b)

FIGURE 3: FM images of crumb rubber asphalt (with and without waste silicone oil). (a) Neat + CR-FM images. (b) Neat + CR + SO-FM images.

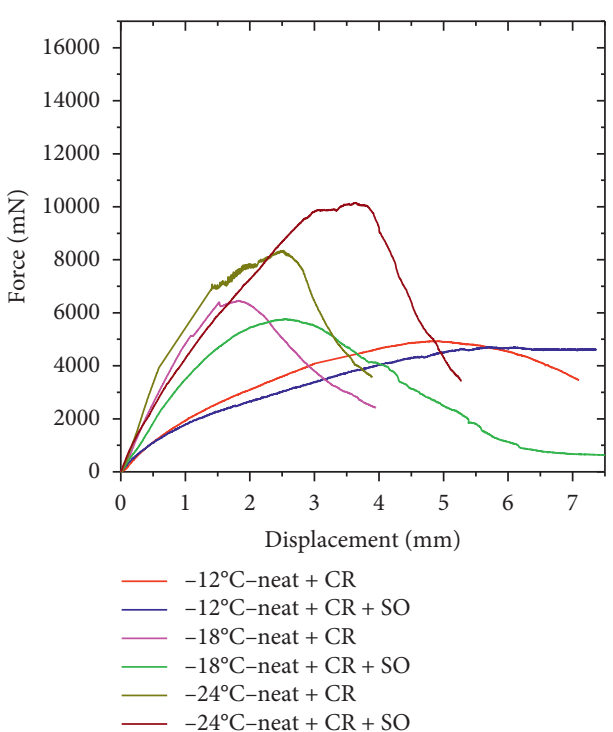

(a)

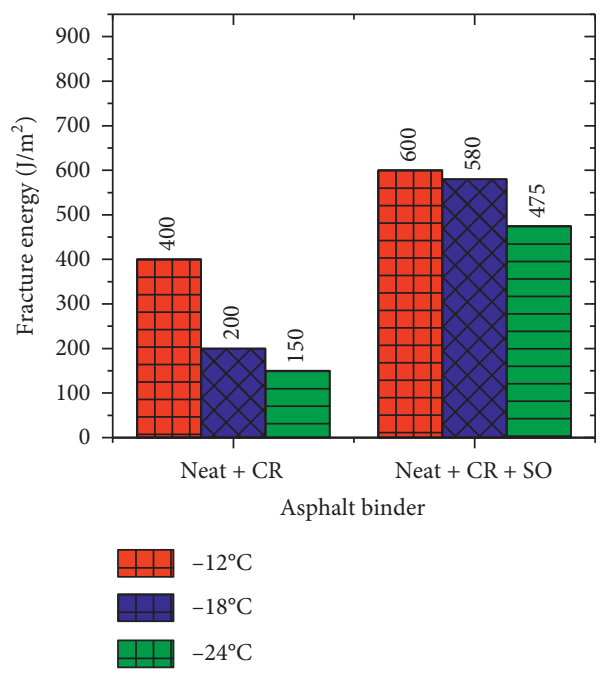

(c)

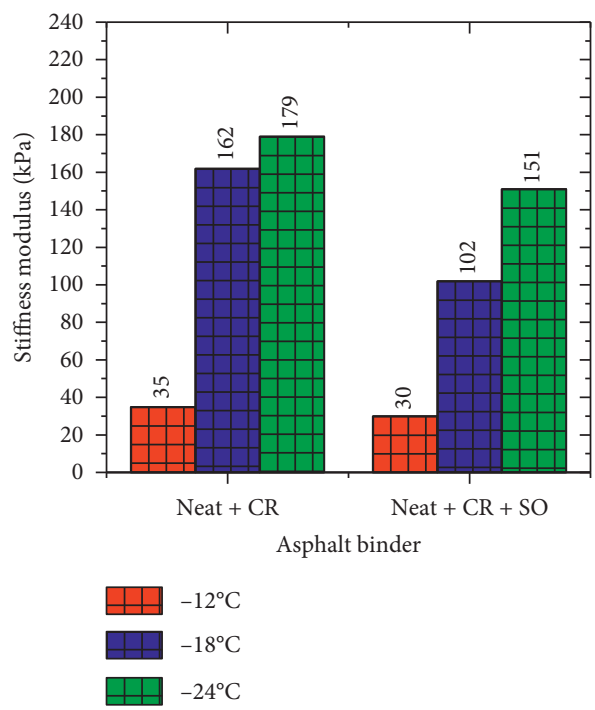

(b)

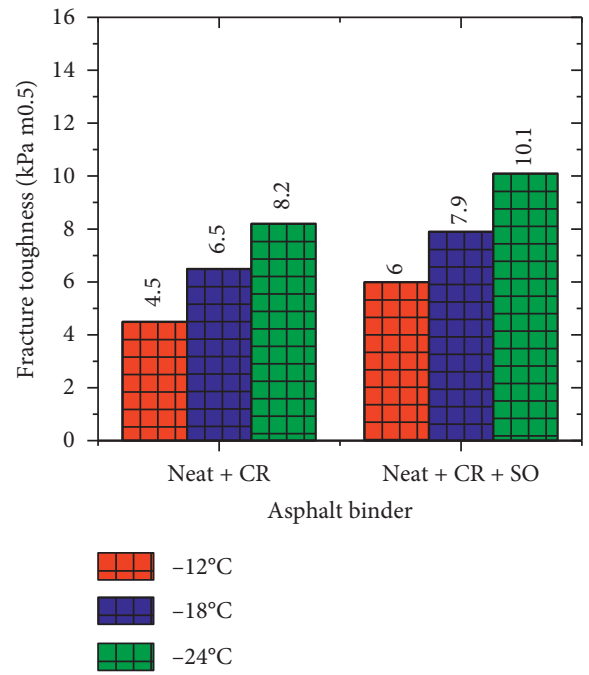

(d)

Figure 4: (a) Force-displacement curves. (b) Change Detection to Stiffness modulus. (c) Fracture energy. (d) Fracture toughness plots. 


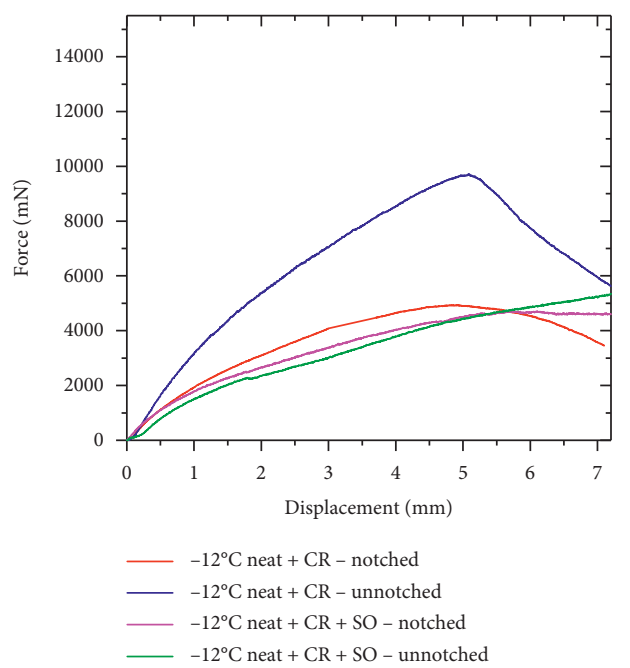

(a)

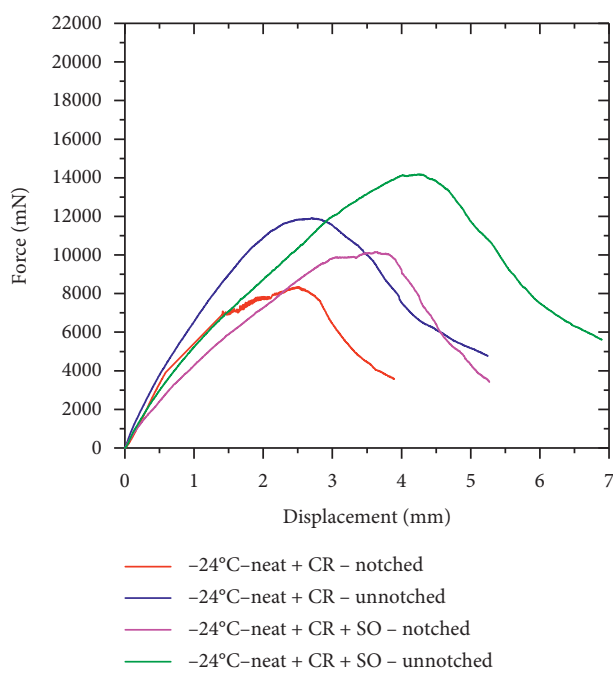

(c)

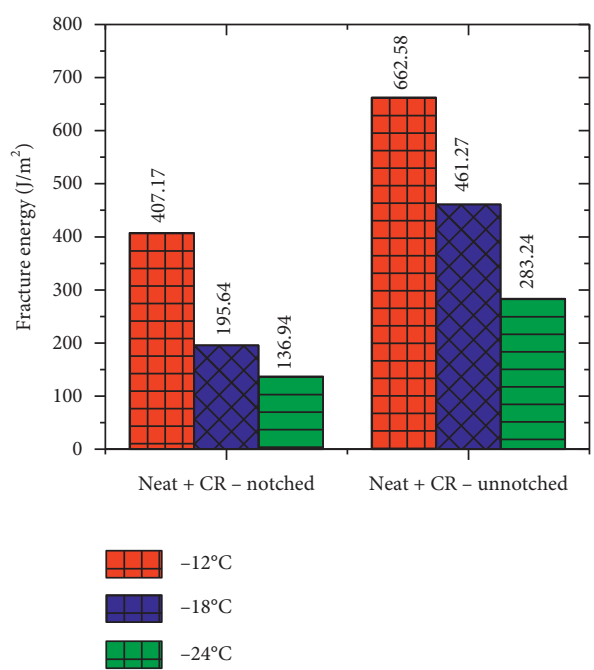

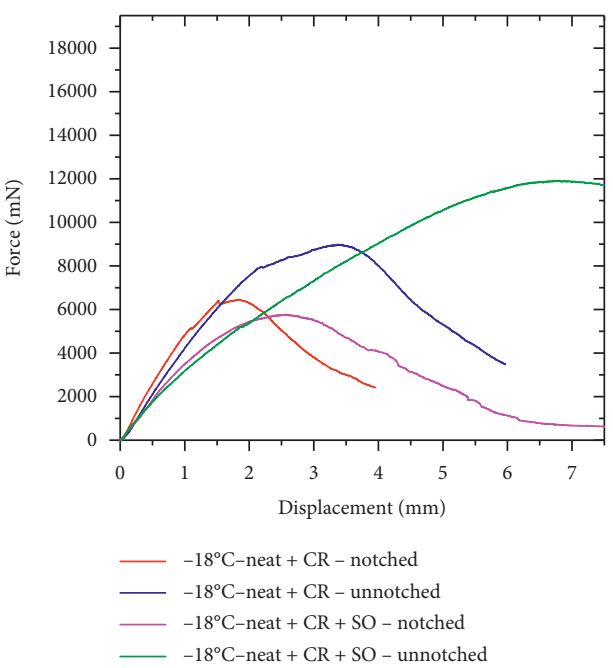

(b)

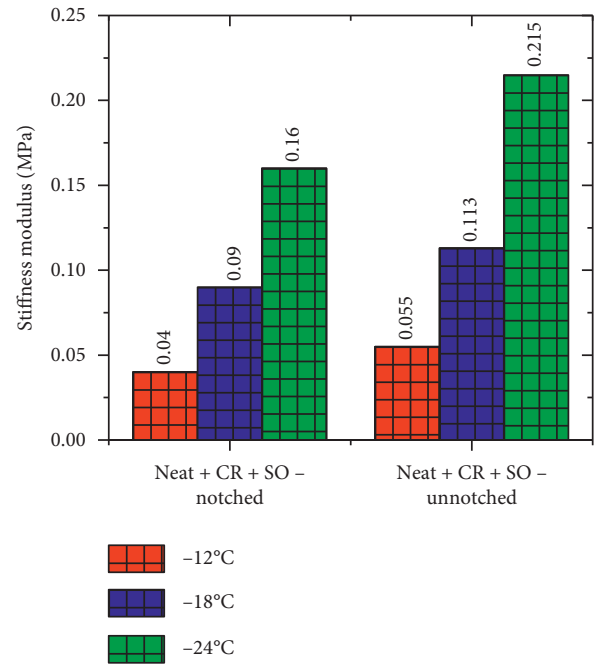

(d)

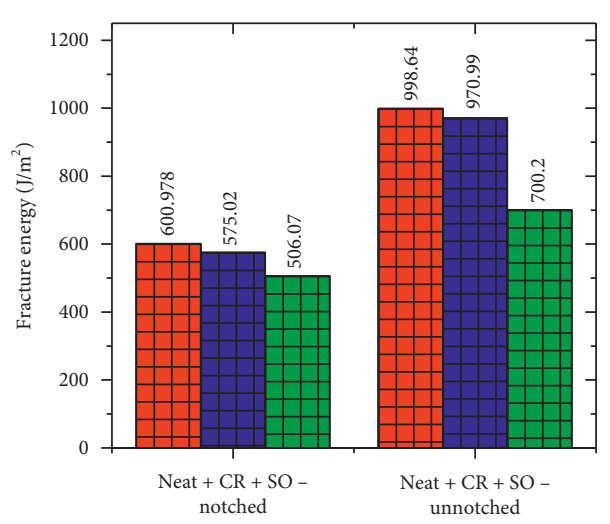

DI $-12^{\circ} \mathrm{C}$
$-18^{\circ} \mathrm{C}$
ㅁ $-24^{\circ} \mathrm{C}$

(e)

Figure 5: Continued. 


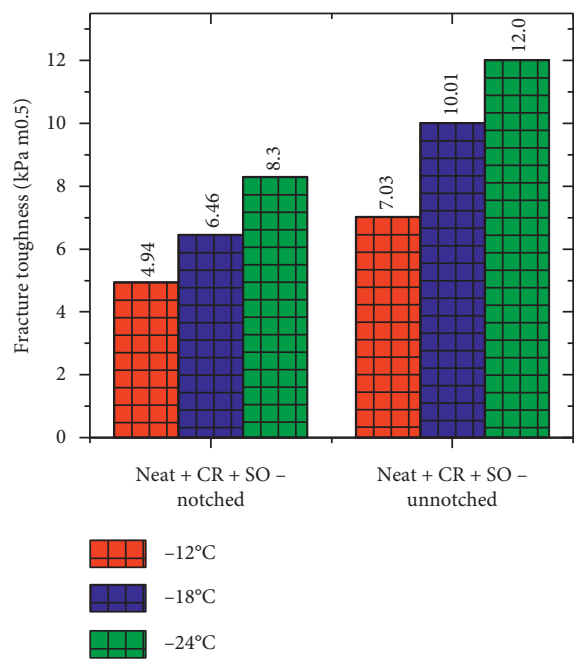

(g)

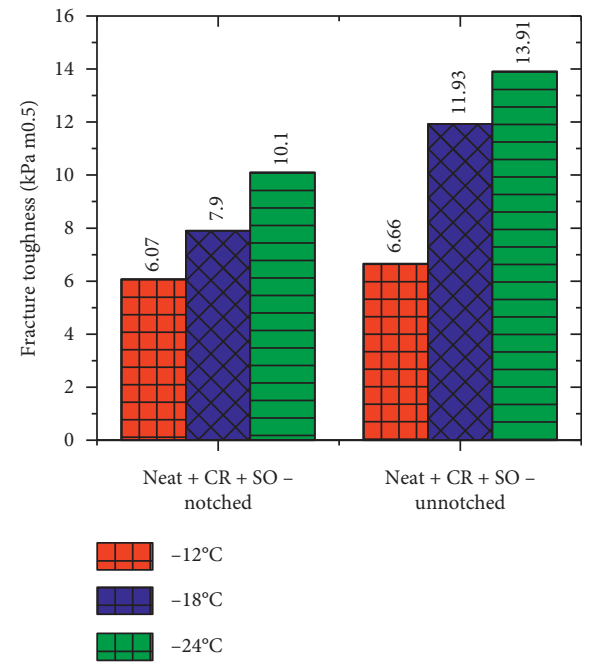

(h)

FIGURE 5: Low-temperature performance of crumb rubber asphalt considering influence of precracked and uncracked notches. Loaddisplacement curves at (a) $-12^{\circ} \mathrm{C}$, (b) $-18^{\circ} \mathrm{C}$, and (c) $-24^{\circ} \mathrm{C}$. (d) Stiffness modulus of asphalt binders. (e) Fracture energy of binders. (f) Fracture energy of binders. (g) Fracture toughness of binders. (h) Fracture toughness of binders.

TABle 4: $T$ test results of displacement at different test temperature.

\begin{tabular}{|c|c|c|c|c|c|c|c|}
\hline Asphalt binder type & Mean $(\mathrm{mm})$ & $N$ & Std. deviation & Std. error mean & $T$ & Df & Sig. \\
\hline $\begin{array}{l}\text { Test temperature: }-12^{\circ} \mathrm{C} \\
\text { Neat }+\mathrm{CR} \\
\text { Neat }+\mathrm{CR}+\mathrm{SO}\end{array}$ & $\begin{array}{l}3.6009 \\
3.2363 \\
\end{array}$ & $\begin{array}{l}3289 \\
3289 \\
\end{array}$ & $\begin{array}{l}2.15842 \\
1.85615 \\
\end{array}$ & $\begin{array}{l}0.3764 \\
0.3237 \\
\end{array}$ & 60.54 & 3288 & 0.001 \\
\hline $\begin{array}{l}\text { Test temperature: }-18^{\circ} \mathrm{C} \\
\text { Neat + CR } \\
\text { Neat + CR + SO }\end{array}$ & $\begin{array}{l}1.9971 \\
1.9999\end{array}$ & $\begin{array}{l}2027 \\
2027\end{array}$ & $\begin{array}{l}1.13464 \\
1.14478\end{array}$ & $\begin{array}{l}0.02520 \\
0.02543\end{array}$ & 8.061 & 2026 & 0.001 \\
\hline $\begin{array}{l}\text { Test temperature: }-24^{\circ} \mathrm{C} \\
\text { Neat + CR } \\
\text { Neat + CR + SO } \\
\end{array}$ & $\begin{array}{l}2.2378 \\
1.5337 \\
\end{array}$ & $\begin{array}{l}1553 \\
1553 \\
\end{array}$ & $\begin{array}{l}1.14058 \\
0.87921 \\
\end{array}$ & $\begin{array}{l}0.02894 \\
0.02231 \\
\end{array}$ & -83.146 & 1552 & 0.001 \\
\hline
\end{tabular}

for unnotched samples than for notched samples. In general, a study found that unnotched binders are more resistant to low-temperature cracking than notched binders. In addition, examining the tested samples, it was observed that for unmodified samples, cracks initiated from the bottom of the sample under the load. Whereas for notched samples, cracks propagated from the preexisted cracks upwards.

6.6. Statistical Analysis of Displacement in Asphalt Binders. Several studies have used the analysis of variance (ANOVA) statistic test to determine the significance of laboratory based experimental results [27, 28]. In this study, the ANOVA test was conducted for purposes of determining whether or not there was a statistically significant difference on low-temperature performance of crumb rubber asphalt binders modified with and without silicone oil. Since asphalt binders having lower deflection $\left(u_{\mathrm{f}}\right)$ at fracture performed very poorly in the field as regards thermal cracking [4], this study used load-deflection values from SENB test in statistical analysis. The higher the deflection values, the better the low temperature cracking resistance. SPSS statistical software was utilized to aid the statistical computations at three temperatures $-12^{\circ} \mathrm{C}$, $-18^{\circ} \mathrm{C}$, and $-24^{\circ} \mathrm{C}$, respectively, by applying one-way ANOVA and a $t$-test and the results of which are presented in Tables 4 and 5, respectively.

Table 4 indicates that the amount of displacement at $-12^{\circ} \mathrm{C}$ was $T(60.54)=0.001, P<0.01$; whereas at $-18^{\circ} \mathrm{C}$, the displacement was $T(8.061)=0.001, P<0.01$; and at $-24^{\circ} \mathrm{C}$, displacement was $T(-83.146)=0.001 \quad(P<0.01)$. Since $P$ values $<0.01$ significance level, the influence of silicone oil on displacement of asphalt samples at different temperatures was found to be statistically significant.

Table 5 indicates that the displacement analysis result at $-12^{\circ} \mathrm{C}$ was $F(5.732)=2.76 e-30(P<0.01)$, whereas that displacement result at $-18^{\circ} \mathrm{C}$ was $F(2.763)=9.76 e-15$ $(P<0.01)$. Finally, displacement result at $-24^{\circ} \mathrm{C}$ was $F$ $(2.662)=0.000174(P<0.01)$. Since all $P$ values are significant at $<0.01$ level, the influence of silicone oil on lowtemperature performance of crumb rubber asphalt is found to be statistically significant.

Standard error (SE) is the estimated standard deviation for the distribution of sample means for an infinite population. The SE values of the estimates of displacement in SENB test were calculated by performing a paired $t$ test. The 
TABLE 5: ANOVA test results of displacement at different test temperatures.

\begin{tabular}{|c|c|c|c|c|c|}
\hline Displacement & Sum of squares & Df & Mean square & $F$ & Sig. \\
\hline \multicolumn{6}{|c|}{ Test temperature: $-12^{\circ} \mathrm{C}$} \\
\hline Between groups & 15196.637 & 3144 & 4.834 & 5.732 & $2.76 e-30$ \\
\hline Within groups & 121.428 & 144 & 0.843 & & \\
\hline Total & 15318.064 & 3288 & & & \\
\hline \multicolumn{6}{|c|}{ Test temperature: $-18^{\circ} \mathrm{C}$} \\
\hline Between groups & 18759.285 & 3730 & 5.029 & 2.763 & $9.76 e-15$ \\
\hline Within groups & 291.212 & 160 & 1.820 & & \\
\hline Total & 19050.497 & 3890 & & & \\
\hline \multicolumn{6}{|c|}{ Test temperature: $-24^{\circ} \mathrm{C}$} \\
\hline Between groups & 5993.014 & 2628 & 2.280 & 2.662 & 0.000174 \\
\hline Within groups & 32.556 & 38 & 0.857 & & \\
\hline Total & 6025.570 & 2666 & & & \\
\hline
\end{tabular}

TABLe 6: Paired sample test results of displacement at different test temperatures for notched samples.

\begin{tabular}{|c|c|c|c|c|c|c|c|c|c|}
\hline \multirow{2}{*}{ Asphalt binder type } & \multirow{2}{*}{$N$} & \multirow{2}{*}{ Mean (mm) } & \multirow{2}{*}{ Std. deviation } & \multirow{2}{*}{ Std. error mean } & \multicolumn{2}{|c|}{$99 \% \mathrm{CI}$} & \multirow{2}{*}{$t$} & \multirow{2}{*}{ Df } & \multirow{2}{*}{ Sig. (2 tailed) } \\
\hline & & & & & Lower & Upper & & & \\
\hline \multicolumn{10}{|c|}{ Test temperature $-12^{\circ} \mathrm{C}$} \\
\hline $\begin{array}{l}\text { Neat + CR } \\
\text { Neat + CR + SO }\end{array}$ & 3289 & -0.36459 & 0.34538 & 0.00602 & -0.3812 & -0.34907 & -60.540 & 3288 & 0.001 \\
\hline \multicolumn{10}{|c|}{ Test temperature $-18^{\circ} \mathrm{C}$} \\
\hline $\begin{array}{l}\text { Neat + CR } \\
\text { Neat + CR + SO }\end{array}$ & 2027 & 0.00272 & 0.01520 & 0.00034 & 0.00185 & 0.00359 & 8.061 & 2026 & 0.001 \\
\hline \multicolumn{10}{|c|}{ Test temperature $-24^{\circ} \mathrm{C}$} \\
\hline $\begin{array}{l}\text { Neat + CR } \\
\text { Neat + CR + SO }\end{array}$ & 2667 & 0.02056 & 0.02075 & 0.00040 & 0.01952 & 0.02159 & 51.163 & 2666 & 0.001 \\
\hline
\end{tabular}

laboratory test results before and after silicone oil treatment to crumb rubber asphalt were compared. The results found that standard error at three temperatures was not more than 0.00602 , as shown in Table 6. Since a smaller value of the standard error of the mean indicates a more precise estimate of the population mean, the results were considered valid.

\section{Conclusion}

In this paper, the effect of silicone oil on dispersion and lowtemperature fracture performance of crumb rubber binder was investigated based on SENB, AFM, and FM tests. Material characterization was analysed by performing the FTIR test. The research was driven by the notion that although CR has succeeded in improving low-temperature performance of asphalt pavements, compatibility between asphalt and crumb rubber still remains a challenge to be solved. As part of an effort to solve the problem and develop sustainable materials, silicone oil was used to improve both rubber particle dispersion in asphalt and low-temperature fracture performance. This study led to following conclusions:

(1) The analysis of molecular structure of silicone confirmed that the material was vinyl silicone oil. Further, the analysis of asphalt modified with silicone oil resulted in generation of new absorption peaks with the main peak having $\mathrm{Si}-\mathrm{O}-\mathrm{Si}$ bond. This bond indicates that silicone oil is a highly hydrophobic material (water repellent) and also has chemical durability which ensures that the silicone oil is applied in asphalt.

(2) The morphological images from the FM test revealed that the addition of silicone oil improves the dispersion of crumb rubber particles in asphalt binder matrix.

(3) The atomic force microscopy results suggested that surface roughness increases with the addition of silicone oil which implied that there was a change in microstructure of the sample. Moreover, the increase in roughness of the surface implied that bonding of asphalt with rubber particles was enhanced, thereby resulting in improved distribution of rubber particles in asphalt.

(4) The addition of crumb rubber to asphalt generally decreased the stiffness of the material at low temperatures. In addition, the study concluded that addition of silicone oil to crumb rubber asphalt resulted in a further decrease of stiffness, thereby improving low-temperature crack resistance. The values of fracture toughness as well as fracture energy indicated that crumb rubber asphalt binders containing silicone oil had superior crack resistance than the one without silicone oil modification.

(5) Analysis of variance and $t$ test results confirmed that the influence of silicone oil on displacement was statistically significant. This means that low-temperature performance of a crumb rubber modified asphalt is strongly influenced by the addition of the silicone oil. 
(6) Furthermore, this study concluded that the improvement in low-temperature performance of crumb rubber modified with silicone oil can be captured from two perspectives. Firstly, as indicated by the analysis of stiffness in FTIR and FM, the silicone oil softened the modified crumb rubber asphalt and enhanced the dispersion of rubber particles in the binder. Softening of asphalt improves crack resistance. Secondly, as seen in IR spectrum, the Si-O bond in silicone oil makes it highly hydrophobic (water repellent) and thus could delay the water penetration and subsequent freezing of asphalt binder during water conditioning of samples at low temperature resulting in lower stiffness.

(7) The comparison between the notched and unnotched samples indicated that the modulus of the notched binders was lower than that of the unnotched one. In addition, the unnotched asphalt binders containing silicone oil did not break at $-12^{\circ} \mathrm{C}$ which confirmed the great influence of silicone oil on rubberised asphalt low-temperature performance.

In spite of results obtained in this study, it should be mentioned that the research had the following limitations: the low-temperature performance of crumb rubber containing SO was limited to SENB test. No BBR test was conducted. Future research can incorporate the BBR test and other techniques to better understand the behaviour of asphalt modified with silicone oil.

\section{Data Availability}

The data used to support the findings of this study are included within the article.

\section{Conflicts of Interest}

The authors declare that there are no conflicts of interest regarding the publication of this article.

\section{Acknowledgments}

The authors would like to express their gratitude to the Harbin Institute of Technology for providing laboratory equipment and materials for experiments. This research was funded by the National Natural Science Foundation of China with Grant nos. 51478152 and 51478154 . Furthermore, the fees relating to the publication of the manuscript was funded by the Copperbelt University in Zambia.

\section{References}

[1] M. Marasteanu, W. Buttlar, H. Bahia et al., Investigation of Low Temperature Cracking in Asphalt Pavements National Pooled Fund Study-Phase II, Minnesota Department of Transportation, Saint Paul, MN, USA, 2012, http://hdl.handle. net/11299/135177.

[2] R. Velasquez and H. Bahia, "Critical factors affecting thermal cracking of asphalt pavements: towards a comprehensive specification," Road Materials and Pavement Design, vol. 14, no. sup1, pp. 187-200, 2013.
[3] E. V. Dave, H. Benjamin, H. Chelsea, M. Jared, and J. Luke, "Implementation of laboratory testing to predict low temperature cracking performance of asphalt pavements," in 8 th RILEM International Symposium on Testing and Characterization of Sustainable and Innovative Bituminous Materials, Springer, Berlin, Germany, 2016.

[4] H. U. Bahia and A. Davies, "Effect of crumb rubber modifiers (CRM) on performance related properties of asphalt binders," Journal of Association of Asphalt Paving Technology, vol. 63, pp. 414-449, 1994.

[5] T. R. Hoare and S. A. M. Hesp, "Low-temperature fracture testing of asphalt binders: regular and modified systems," Transportation Research Record: Journal of the Transportation Research Board, vol. 1728, no. 1, pp. 36-42, 2000.

[6] P. E. Sebaaly, V. T. Gopal, and J. A. Epps, "Low temperature properties of crumb rubber modified binders," Road Materials and Pavement Design, vol. 4, no. 1, pp. 29-49, 2003.

[7] S.-S. Kim, Z. D. Wysong, and J. Kovach, "Low-temperature thermal cracking of asphalt binder by asphalt binder cracking device," Transportation Research Record: Transportation Research Record: Journal of the Transportation Research Board, vol. 1962, no. 1, pp. 28-35, 2006.

[8] A. Zofka and A. Braham, "Comparison of low-temperature field performance and laboratory testing of 10 test sections in the midwestern United States," Transportation Research Record: Journal of the Transportation Research Board, vol. 2127, no. 1, pp. 107-114, 2009.

[9] M. Pszczoła, J. Mariusz, S. Cezary, J. Józef, and D. Bohdan, "Evaluation of low temperature properties of rubberized asphalt mixtures," Procedia Engineering, vol. 172, pp. 897-904, 2017.

[10] P. S. Wulandari and D. Tjandra, "Use of crumb rubber as an additive in asphalt concrete mixture," Procedia Engineering, vol. 171, pp. 1384-1389, 2017.

[11] M. Mull, M A. Stuart, and K. Yehia, "Fracture resistance characterization of chemically modified crumb rubber asphalt pavement," Journal of Materials Science, vol. 37, no. 3, pp. 557-566, 2002.

[12] A. Hussain and S. A Elmasry, "Chemically modified crumb rubber effects on rubberized asphalt properties," International Journal of Environmental Sciences, vol. 2, no. 4, pp. 158-162, 2013.

[13] S. Zhihao, Z.-J. Wang, and G. Y. Xie, "Preparation and performances of silicone modified asphalt," Fine and Special Chemical, vol. 11, 2017.

[14] Y. Li, Y. Zhang, and Y. Zhang, "Mechanical properties of high-density polyethylene/scrap rubber composites modified with ethylene-propylene-diene terpolymer, dicumyl peroxide and silicone oil," Journal of Applied Polymer Science, vol. 88, no. 8, pp. 2020-2027, 2003.

[15] C. Peng, H. Zhang, Y. Zhanping et al., "Preparation and antiicing properties of a superhydrophobic silicone coating on asphalt mixture," Construction and Building Materials, vol. 189, pp. 227-235, 2018.

[16] C. Gorkem and S. Burak, "Predicting stripping and moisture induced damage of asphalt concrete prepared with polymer modified bitumen and hydrated lime," Construction and Building Materials, vol. 23, no. 6, pp. 2227-2236, 2009.

[17] J. Lin, C. Meizhu, W. Shaopeng et al., "Utilization of silicone maintenance materials to improve the moisture sensitivity of asphalt mixtures," Construction and Building Materials, vol. 33, pp. 1-6, 2012.

[18] R. Zhang, Y. Zhanping, W. Hainian, Y. Mingxiao, K. Y. Yoke, and S. Chundi, "The impact of bio-oil as rejuvenator for aged 
asphalt binder," Construction and Building Materials, vol. 196, pp. 134-143, 2019.

[19] W. H. Daly, Relationship between Chemical Makeup of Binders and Engineering Performance (No. Project 20-015 (Topic 4713))Atomic Force Microscopy (AFM), 2017.

[20] S. Iliuta, A. M. H. Simon, O. M. Mihai, M. Tony, and K. T. Kai, "Field validation study of low-temperature performance grading tests for asphalt binders," Transportation Research Record: Journal of Transportation Board, vol. 1875, no. 1, pp. 14-21, 2004.

[21] H. Bahia, R. Velasquez, H. Tabatabaee, and S. Puchalski, "The role of asphalt binder fracture properties in thermal cracking performance of mixtures and pavements," in Proceedings of the CTAA Annual Conference, Vancouver, Canada, November 2012.

[22] A. Groza, A. Surmeian, and M. Ganciu, "Infrared spectral investigation of organosilicon compounds under corona charge injection in air at atmospheric pressure," Journal of Optoelectronics and Advanced Materials, vol. 7, no. 5, pp. 2545-2548, 2005.

[23] Q. F. An, K. Guo, M. T. Li, and L. X. Huang, "Synthesis and characterization of polyether-b-polysiloxane and its application in antifoaming agent," Silicone Material, vol. 6, 2008.

[24] Q. Yang and X. Li, "Mechanism and effectiveness of a siliconebased warm mix additive," Journal of Materials in Civil Engineering, vol. 31, no. 1, Article ID 04018336, 2019.

[25] A. Kanabar, "Physical and chemical aging behavior of asphalt cements from two northern Ontario pavement trials," Doctoral dissertation, Queen's University, Kingston, Canada, 2010.

[26] K. W. Kim, J. K. Seung, S. D. Young, and T.-S. Park, "Fracture toughness of polymer-modified asphalt concrete at low temperatures," Canadian Journal of Civil Engineering, vol. 30, no. 2, pp. 406-413, 2003.

[27] T. Gandhi, "Effects of warm asphalt additives on asphalt binder and mixture properties," Doctoral thesis, Clemson University, Clemson, SC, USA, 2008,https://tigerprints. clemson.edu/all_dissertations/203/.

[28] C. Akisetty, F. Xiao, T. Gandhi, and S. Amirkhanian, "Estimating correlations between rheological and engineering properties of rubberized asphalt concrete mixtures containing warm mix asphalt additive," Construction and Building $\mathrm{Ma}$ terials, vol. 25, no. 2, pp. 950-956, 2011. 


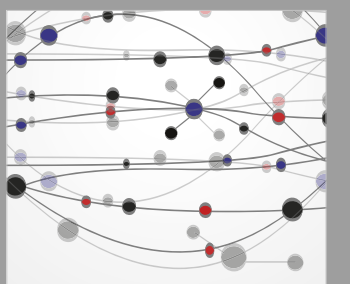

The Scientific World Journal
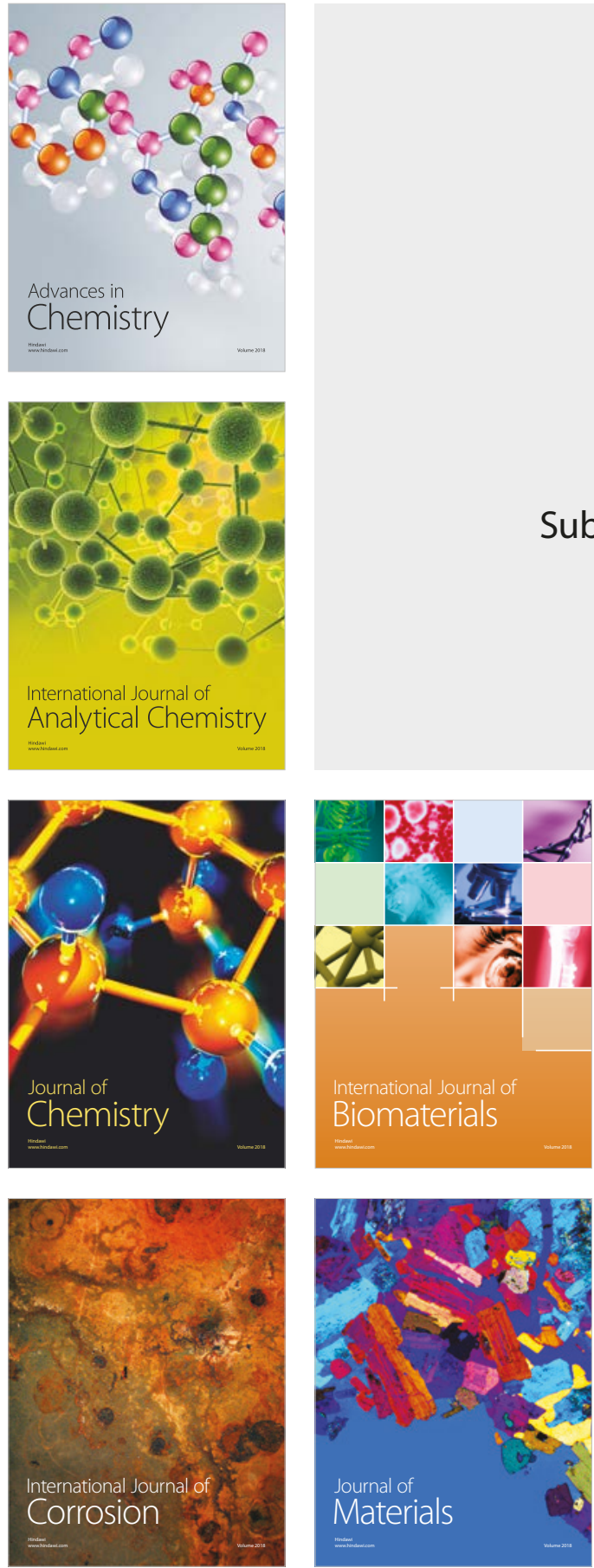

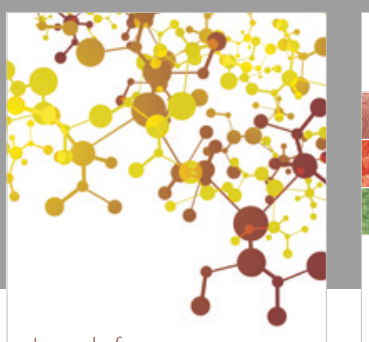

Journal of

Applied Chemistry
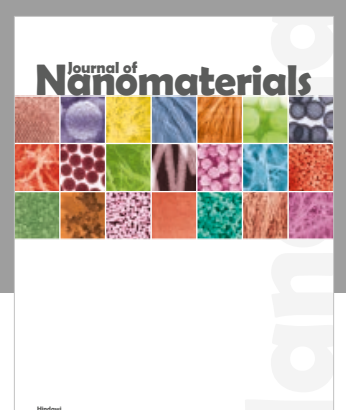

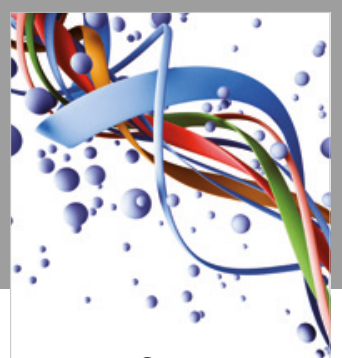

Scientifica

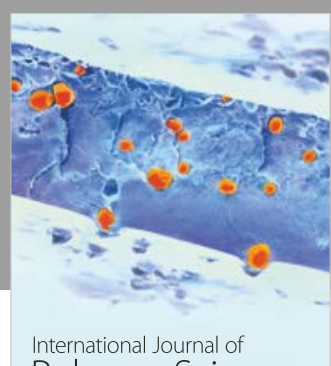

Polymer Science

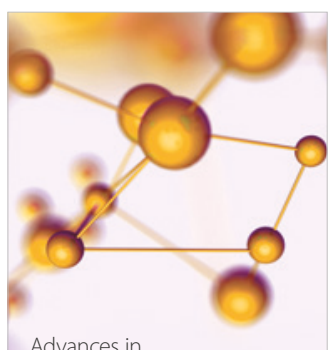

Physical Chemistry
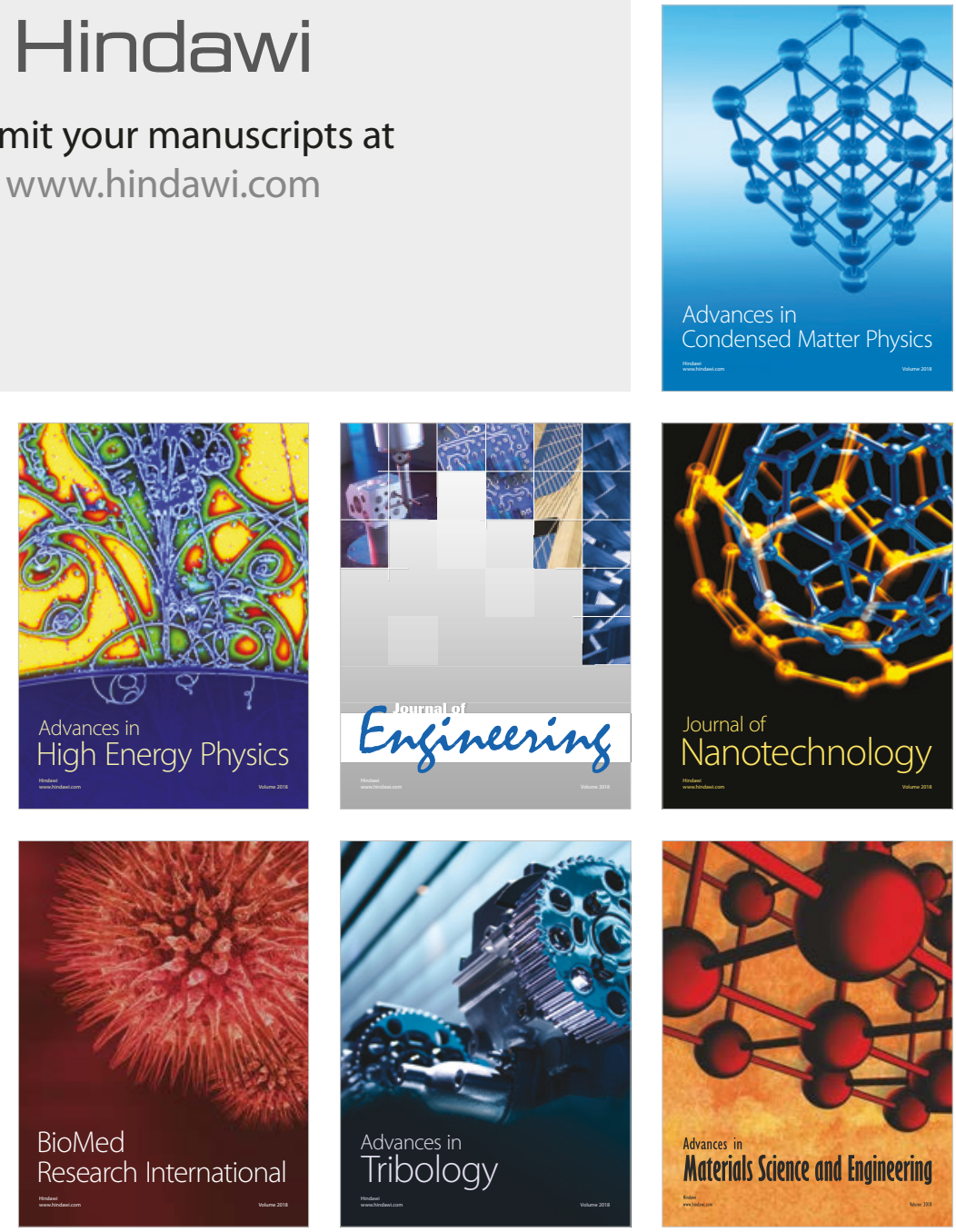